\title{
Correção da acidez e mobilidade de íons em Latossolo com aplicação superficial de escória, lama cal, lodos de esgoto e calcário
}

\author{
Juliano Corulli Corrêa ${ }^{(1)}$, Leonardo Theodoro Büll(1), Carlos Alexandre Costa Crusciol(1), Rafael Marcelino(1) \\ e Munir Mauad(2)
}

\begin{abstract}
(1)Universidade Estadual Paulista, Fac. de Ciências Agronômicas, Fazenda Experimental Lageado, Caixa Postal 237, CEP $18603-970$ Botucatu, SP. E-mail: correajc@fca.unesp.br, bull@fca.unesp.br, crusciol@fca.unesp.br,rmarcelino@fca.unesp.br(2)Universidade para o Desenvolvimento do Estado e da Região do Pantanal, Av. Herculano Alexandre, 1400, Caixa Postal 2153, CEP 79037-280 Campo Grande, MS. E-mail:munirmauad@hotmail.com
\end{abstract}

\begin{abstract}
Resumo - Com o objetivo de avaliar a correção da acidez, saturação por bases e a mobilidade de nitrato, cálcio e magnésio no perfil de um Latossolo Vermelho distrófico, foi conduzido experimento em condições de campo, em área sob sistema plantio direto, de 2002 a 2005. A possível interferência dos ácidos orgânicos, provenientes da aveia-preta, decorrentes da aplicação superficial de escória de aciaria, lama cal e lodos de esgoto centrifugado e de biodigestor, foram igualmente avaliadas nas doses de 0 (testemunha), 2, $4 \mathrm{e} 8 \mathrm{t} \mathrm{ha}^{-1} \mathrm{e} \mathrm{um}$ tratamento adicional composto pela calagem superficial na dose de $2 \mathrm{t} \mathrm{ha}^{-1}$. A aplicação superficial de doses crescentes de escória de aciaria, lama cal e lodo de esgoto centrifugado permitiu verificar aumento do valor de $\mathrm{pH}$ no solo. Esses resíduos e o lodo de esgoto de biodigestor elevaram a saturação por bases e a disponibilidade de nitrato, cálcio e magnésio até a profundidade de $40 \mathrm{~cm}$ no solo, com apenas três meses de reação. A pequena quantidade de ácidos orgânicos na parte aérea da aveia-preta não justificou o rápido deslocamento dos nutrientes e da neutralização do solo em subsuperfície. Os resíduos escória de aciaria, lama cal e lodo de esgoto centrifugado podem ser utilizados como corretivos da acidez e aplicados sobre a superfície do solo no sistema de plantio direto.
\end{abstract}

Termos para indexação: Avena sativa, Glycine max, ácidos orgânicos, plantio direto.

\section{Liming and ion mobility in an Oxisol under surface application of flue dust, aqueous lime, sewage sludge and limestone}

\begin{abstract}
The experiment was carried out under field conditions in a no-tillage system from 2002 to 2005, aiming to evaluate liming, base saturation and nitrate, calcium and magnesium mobility in a dystrophic Clay Rhodic Hapludox soil. The possible interference of organic acid catering of black oat through surface application of flue dust, aqueous lime and sewage sludge from a centrifuge and a biodigestor were also evaluated at rates of zero (control), 2, 4 and $8 \mathrm{tha}^{-1}$ as well as an additional treatment of dolomitic limestone at the rate of $2 \mathrm{tha}^{-1}$. Due to the increasing surface applications of flue dust, aqueous lime and sewage sludge from a centrifuge, soil $\mathrm{pH}$ value increased; these three residues and the sewage sludge from a biodigestor increased base saturation and availability of nitrate, calcium and magnesium up to the depth of $40 \mathrm{~cm}$ and within three months only. The low concentration of organic acid in the aerial part of the black oat did not explain the quicky nutrient leaching and soil acidity neutralization in depth. Flue dust, aqueous lime and sewage sludge from a centrifuge can be used as an acidity corrective and applied on the soil surface in no-tillage system.
\end{abstract}

Index terms: Avena sativa, Glycine max, organic acid, no-tillage.

\section{Introdução}

Estudos sobre aplicação de calcário em solos sob plantio direto vêm sendo conduzidos com relativa frequiência no Brasil (Amaral et al., 2004a, 2004b; Fidalski \& Tormena, 2005; Caires et al., 2006). Há também trabalhos desenvolvidos com outros materiais corretivos de acidez do solo como os silicatos (Prado \& Fernandes 2003; Carvalho-Pupatto 2004; Ramos et al., 2006) e lodos de esgoto (Melo et al., 2001; Oliveira et al., 2002; Nascimento et al., 2004), porém incorporados ao solo. A avaliação da aplicação desses materiais em solos sob plantio direto não é conhecida. 
Os resíduos: escória de aciaria, lama cal e alguns lodos de esgoto têm a capacidade de neutralizar a acidez e possibilitar o deslocamento de nutrientes no perfil do solo, e podem ser usados como materiais alternativos ao

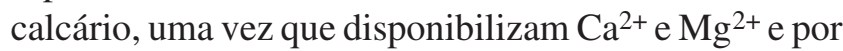
existir em sua composição $\mathrm{CaO}, \mathrm{CaOH}, \mathrm{SiCO}_{3}, \mathrm{NaOH}$, além de $\mathrm{CaCO}_{3}$ e $\mathrm{MgCO}_{3}$ (Oliveira et al., 2002; Carvalho-Pupatto, 2004; Ramos et al., 2006).

É provável que a escória de aciaria, lama cal e lodos de esgoto tenham a vantagem de reduzir a acidez do solo mais rapidamente que o calcário, até mesmo em profundidade, uma vez que apresentam óxidos e hidróxidos de cálcio (lodos de esgoto centrifugados e na lama cal) e silicatos (escória de aciaria), compostos mais solúveis que os carbonatos contidos no calcário, permitindo que os produtos da reação de dissociação apresentem maior mobilidade no solo (Alcarde, 1992; Quaggio, 2000).

A prática da calagem realizada sobre a superfície do solo, no sistema de plantio direto, tem se mostrado eficaz na redução da acidez do solo e na disponibilidade de nutrientes $(\mathrm{Ca} \mathrm{e} \mathrm{Mg})$, principalmente nas camadas mais superficiais, até $10 \mathrm{~cm}$ (Amaral et al., 2004a; Alleoni et al., 2005) e, em alguns casos, nas camadas subsuperficiais, para profundidades iguais ou superiores a $20 \mathrm{~cm}$ (Mello et al., 2003; Fidalski \& Tormena, 2005; Caires et al., 2006).

Para ocorrer a variação de $\mathrm{pH}$, de saturação por bases e a mobilidade de cátions básicos no perfil do solo é fundamental a ausência de cátions ácidos nas camadas mais superficiais; uma vez que a prioridade das ligações será com esses cátions ácidos, vale lembrar que a redução desses cátions ácidos ocorre quando o pH em água atinge valores de 5,2 e 5,5 (Rheinheimer et al., 2000). O deslocamento de cátions básicos $\left(\mathrm{K}^{+}, \mathrm{Ca}^{2+} \mathrm{e}\right.$ $\mathrm{Mg}^{2+}$ ) é ainda dificultado com a adsorção pelas cargas negativas variáveis geradas com a elevação do $\mathrm{pH}$ (Caires et al., 2004). Portanto, a mobilidade dos cátions básicos no perfil do solo pode ser favorecida quando eles formarem pares iônicos, e isto só ocorrerá quando a constante de estabilidade do cátion básico-ligante for maior que a do cátion básico-solo e a constante de estabilidade de cátions ácidos-ligantes for menor que a dos cátions ácidos-solo (Amaral et al., 2004b).

A formação de pares iônicos entre os cátions do solo e os compostos inorgânicos pode ocorrer com os próprios produtos da dissolução do corretivo ou de ânions liberados pela exudação radicular na rizosfera como $\mathrm{OH}^{-} \mathrm{e}^{\mathrm{HCO}_{3}}$, além de outros ânions como nitrato $\left(\mathrm{NO}_{3}{ }^{-}\right)$, sulfato $\left(\mathrm{SO}_{4}{ }^{2-}\right)$ e cloreto $\left(\mathrm{Cl}^{-}\right)$, provenientes da mineralização de adubos ou da decomposição de resíduos vegetais do solo pelos microrganismos, na camada superficial (Rosolem et al., 2003). Os pares iônicos orgânicos são formados por cátions do solo com compostos hidrossolúveis de baixo peso molecular, os quais também têm origem na decomposição de resíduos vegetais e na exudação radicular, através de radicais COOH (Franchini et al., 2001, 2003). É provável que pares iônicos inorgânicos tenham atuação maior do que os orgânicos em razão da maior quantidade desses íons no solo, e mesmo porque os ácidos orgânicos têm vida útil muito curta, e sua atuação na neutralização da acidez do solo fica restrita à camada superficial de $2,5 \mathrm{~cm}$ (Amaral et al., 2004a).

O objetivo deste trabalho foi avaliar a variação do $\mathrm{pH}$, da saturação por bases e o deslocamento de nitrato, cálcio e magnésio ao longo do perfil do solo assim como a possível interferência de ácidos orgânicos decorrente da aplicação superficial de escória de aciaria, lama cal e lodos de esgoto centrifugado e de biodigestor em solo sob sistema plantio direto.

\section{Material e Métodos}

O experimento foi desenvolvido durante os anos agrícolas de 2002 a 2005, na Fazenda Experimental Lageado da Faculdade de Ciências Agronômicas da Unesp, Botucatu, SP, na latitude de 22051'15"S, longitude de $48^{\circ} 26^{\prime} 30^{\prime \prime} \mathrm{W}$ e altitude de $740 \mathrm{~m}$. Segundo a classificação climática de Köppen, o clima predominante é do tipo Cwb.

Antes da instalação do trabalho, a área experimental já estava sendo conduzida no sistema de plantio direto, sendo instaladas anteriormente a seguinte sequiência de culturas: soja, aveia, milho e um ano em pousio. Em maio de 2002, houve a dessecação da vegetação local e posterior semeadura do feijão-guandu (Cajanus cajan), sem adubação de semeadura e de cobertura, e em agosto, aos 80 dias após a emergência desse adubo verde, realizou-se sua dessecação e posterior montagem do experimento.

O trabalho foi implantado sob sistema de plantio direto em Latossolo Vermelho distrófico, textura média, fase campo subtropical, relevo suave ondulado (Embrapa, 1999). A amostragem da caracterização química do solo foi realizada em 15 pontos aleatórios da área (subamostra) a fim de compor uma amostra composta de solo (Tabela 1), nas profundidades de $0-5,5-10$, 
10-20 e 20-40 cm, de acordo com método descrito por Raij et al. (2001).

Os tratamentos constituíram-se na utilização de quatro resíduos: dois tipos de lodo de esgoto, um centrifugado com adição de cal virgem $(\mathrm{CaO})$ da estação de tratamento de esgoto (ETE) de São José dos Campos (LC) e o segundo, de biodigestor com adição de polieletrólitos da ETE de Barueri (LB); e dois resíduos industriais, escória de aciaria da Empresa Mannesmann (E) e o segundo lama cal da empresa de celulose Luwarcel (Lcal), cujos resultados da caracterização química estão apresentados na Tabela 2. Foram empregadas doses equivalentes a 0 (testemunha), $2,4 \mathrm{e}$ $8 \mathrm{t} \mathrm{ha}^{-1}$ para cada resíduo. Também foi utilizado um tratamento-controle, o qual correspondeu à aplicação de calcário dolomítico $\left(280 \mathrm{~g} \mathrm{~kg}^{-1}\right.$ de $\mathrm{CaO}, 230 \mathrm{~g} \mathrm{~kg}^{-1}$ de $\mathrm{MgO}$ e PRNT de 71,29\%) na dose recomendada pelo método de saturação por bases $\left(2 \mathrm{tha}^{-1}\right)$ a fim de elevar este índice a $60 \%$, com base de cálculo para a profundidade de 0-20 $\mathrm{cm}$, para produção de soja (Raij et al., 1996).

A fim de se determinar o poder de neutralização dos resíduos, foi montado um experimento preliminar que consistiu da incubação em casa de vegetação por 30 dias de cada resíduo, em diferentes dosagens, em sacos de plástico contendo $1 \mathrm{~kg}$ do Latossolo, com teor de umidade de $70 \%$ da capacidade de campo (Tsutiya et al., 2001; Melo et al., 2001).

Antes da instalação do experimento, determinou-se a quantidade de metais pesados presentes em cada resíduo
(Tabela 2), empregando-se o método descrito pelo Laboratório Nacional de Referência Vegetal (1983). As leituras foram analisadas em espectrofotômetro de emissão em plasma induzida em argônio (ICP/AES), comparando-se os valores dos resíduos industriais (Lcal e E) às quantidades permitidas na norma de aplicação de resíduos sólidos de acordo com a NBR 10004/1987 (Súmula dos padrões..., [s.d.]) e os valores dos lodos de esgoto (LB e LC) à legislação imposta pela Cetesb P4230 de agosto 1999. Os quatro resíduos apresentaram resultados inferiores aos valores limítrofes propostos pela legislação brasileira.

Foram determinados a reatividade (RE), o poder neutralizante $(\mathrm{PN})$ e o poder relativo de neutralização total (PRNT) da lama cal, lodos de esgoto (LC e LB), escória de aciaria e calcário pelo método descrito em Laboratório Nacional de Referência Vegetal (1983), (Tabela 3), o que torna possível a comparação entre os tratamentos como materiais corretivos da acidez.

Os resíduos escória de aciaria (E), lama cal (Lcal) e lodo de esgoto centrifugado (LC) podem ser utilizados como materiais corretivos da acidez, em razão de seus conteúdos em material neutralizante, granulometria e natureza de composição atenderem às exigências da legislação brasileira, apresentada pelo Ministério da Agricultura (Tabela 3), que tem como base o trabalho de Alcarde et al. (1992). Apenas a utilização do lodo de esgoto de biodigestor (LB) como material corretivo de acidez não é permitida.

Tabela 1. Caracterização química original do Latossolo Vermelho distrófico, utilizado como base experimental, em diferentes profundidades.

\begin{tabular}{|c|c|c|c|c|c|c|c|c|c|c|c|c|}
\hline \multirow{2}{*}{$\begin{array}{l}\text { Profundidade } \\
(\mathrm{cm})\end{array}$} & \multirow{2}{*}{$\begin{array}{c}\mathrm{pH} \\
\mathrm{CaCl}_{2}\end{array}$} & \multirow{2}{*}{$\begin{array}{c}\mathrm{MO} \\
\left(\mathrm{g} \mathrm{dm}^{-3}\right)\end{array}$} & \multirow{2}{*}{$\begin{array}{c}\mathrm{P}_{\text {res }} \\
\left(\mathrm{mg} \mathrm{dm}^{-3}\right)\end{array}$} & $\mathrm{Al}^{3+}$ & $\mathrm{H}+\mathrm{Al}$ & $\mathrm{K}$ & $\mathrm{Ca}$ & $\mathrm{Mg}$ & SB & CTC & $\mathrm{S}$ & $\mathrm{V} \%$ \\
\hline & & & & \multicolumn{9}{|l|}{------ } \\
\hline $0-5$ & 4,0 & 16 & 6 & 7 & 38 & 0,6 & 12 & 6 & 19 & 57 & 12 & 33 \\
\hline $5-10$ & 4,0 & 18 & 6 & 6 & 45 & 1,0 & 19 & 9 & 29 & 74 & 5 & 39 \\
\hline $10-20$ & 4,2 & 15 & 5 & 5 & 45 & 0,7 & 13 & 5 & 19 & 64 & 5 & 30 \\
\hline $20-40$ & 3,9 & 10 & 4 & 6 & 42 & 0,6 & 12 & 3 & 16 & 58 & 6 & 27 \\
\hline
\end{tabular}

Tabela 2. Resultados da análise química dos resíduos industriais e urbanos utilizados como tratamentos do experimento sob plantio direto.

\begin{tabular}{|c|c|c|c|c|c|c|c|c|c|c|c|c|c|}
\hline Resíduos & $\begin{array}{c}\text { Umid } \\
(\%)\end{array}$ & $\mathrm{pH}$ & $\mathrm{K}_{2} \mathrm{O}$ & $\begin{array}{r}N \\
-(g\end{array}$ & $\begin{array}{c}\mathrm{Ca} \\
-1)\end{array}$ & $\mathrm{Mg}$ & $\mathrm{S}$ & As & $\mathrm{Cd}$ & $\begin{array}{c}\mathrm{Cr} \\
-(\mathrm{mg} \mathrm{kg}\end{array}$ & $\mathrm{Hg}$ & $\mathrm{Ni}$ & $\mathrm{Pb}$ \\
\hline$\overline{\mathrm{LC}}$ & 5 & 12 & 0,3 & 2,5 & 28 & 0,4 & 0,5 & 14,0 & $-^{(1)}$ & 4 & - & 7 & 17 \\
\hline LB & 29 & 7 & 0,2 & 4,0 & 2 & 0,4 & 1,6 & 27,0 & 0,1 & 19 & - & 180 & 107 \\
\hline Lcal & 19 & 12 & 0,1 & 0,4 & 37 & 0,6 & 0,3 & 1,4 & - & 13 & - & 96 & 60 \\
\hline $\mathrm{E}$ & 2 & 12 & 0,1 & 0,3 & 23 & 2,1 & --- & 5,0 & - & 61 & - & 19 & 308 \\
\hline$\overline{\text { Cetesb }}^{(2)}$ & & & & & & & & 75 & 85 & 3.000 & 57 & 420 & 840 \\
\hline NBR $10004^{(3)}$ & & & & & & & & 1.000 & n.a. ${ }^{(4)}$ & n.a & 100 & n.a. & 1.000 \\
\hline
\end{tabular}

(1) Traços. ${ }^{(2)}$ Legislação para os limites máximos de metais pesados para lodos de esgoto imposta pela Cetesb (1999), Lei P4230. (3)Legislação para os limites máximos de metais pesados para resíduos sólidos imposta pela ABNT, Lei NBR 10004, 1987. (4)Não-aplicável (não descrito o limite na NBR 10004). 
Os tratamentos foram distribuídos no campo em delineamento em blocos ao acaso com esquema fatorial $4 \times 4+1$, com quatro repetições. Em cada bloco as parcelas foram dimensionadas com $6 \mathrm{~m}$ de largura por $7 \mathrm{~m}$ de comprimento, deixando-se $1 \mathrm{~m}$ entre as parcelas do mesmo bloco e $3 \mathrm{~m}$ entre blocos.

O experimento iniciou-se com a dessecação do feijãoguandu (Cajanus cajan), o qual produziu $7.400 \mathrm{~kg} \mathrm{ha}^{-1}$ de fitomassa seca, obtendo-se os teores de $8 \mathrm{~g} \mathrm{~kg}^{-1}$ de $\mathrm{Ca}, 3,2 \mathrm{~g} \mathrm{~kg}^{-1}$ de $\mathrm{Mg}, 13 \mathrm{~g} \mathrm{~kg}^{-1}$ de N e $1,6 \mathrm{~g} \mathrm{~kg}^{-1}$ de $\mathrm{S}$. Quando a palhada do adubo verde estava seca e acamada, em agosto de 2002, foram aplicados a lanço, sobre essa palhada, os tratamentos com escória de aciaria, lama cal, lodos de esgoto centrifugado e de biodigestor de acordo com suas respectivas doses, bem como o calcário na dose de $2 \mathrm{t} \mathrm{ha}^{-1}$. A aplicação dos tratamentos antecedeu três meses a semeadura da soja na safra 2002/2003, e a precipitação pluvial nesse período de reação correspondeu a 270 mm. Em 2003, 2004 e até final da última amostragem química a soma do volume de precipitação atingiu $2.850 \mathrm{~mm}$.

Durante o experimento foram realizados três cultivos de soja (2002/2003, 2003/2004 e 2004/2005) aplicando-se adubação anual de $60 \mathrm{~kg} \mathrm{ha}^{-1}$ de $\mathrm{P}_{2} \mathrm{O}_{5}$ e $30 \mathrm{~kg} \mathrm{ha}^{-1}$ de $\mathrm{K}_{2} \mathrm{O}$, com sementes com inoculação de Bradyrhizobium japonicum. Durante o inverno, cultivou-se por dois anos aveia-preta (2003 e 2004) aplicando-se $45 \mathrm{~kg} \mathrm{ha}^{-1} \mathrm{de} \mathrm{N} \mathrm{na}$ forma de uréia, com a finalidade de produção de massa verde e, posteriormente, palhada. Para as cinco culturas instaladas na área, entre 2002 e 2005, foi adotado o sistema de plantio direto.

Antes da semeadura da soja (2002/2003), realizou-se a amostragem de solo para a caracterização química nas profundidades de $0-5,5-10,10-20$ e $20-40 \mathrm{~cm}$, utilizando-se um trado do tipo sonda, coletando-se quatro amostras por parcela, a fim de constituir uma amostra composta, seguindo-se os mesmos procedimentos em 2004 e 2005, todos anteriores à semeadura da soja.

Tabela 3. Resultados em porcentagem de partículas retidas nas peneiras de $10(\varnothing=2 \mathrm{~mm}), 20(\varnothing=0,84 \mathrm{~mm})$, $50(\varnothing=0,30 \mathrm{~mm})$ e fundo, e reatividade (RE), poder neutralizante (PN) e poder relativo de neutralização total (PRNT).

\begin{tabular}{lcrrrcrr}
\hline Resíduos & Pen 10 & Pen 20 & Pen 50 & Fundo & RE & PN & PRNT \\
\hline Lcal & 0,00 & 0,00 & 0,05 & 99,95 & 99,98 & 99,00 & 98,98 \\
LC & 2,40 & 14,63 & 40,10 & 42,87 & 69,85 & 93,00 & 65,00 \\
E & 2,20 & 6,15 & 32,53 & 59,10 & 79,80 & 60,00 & 47,88 \\
LB & 0,09 & 50,23 & 35,46 & 14,22 & 36,50 & 3,00 & 1,09 \\
Calcário & 0,00 & 4,20 & 18,80 & 77,00 & 89,12 & 80,00 & 71,29 \\
\hline
\end{tabular}

Foram determinados nestas amostras o $\mathrm{pH}$ em $\mathrm{CaCl}_{2}$, $\mathrm{H}+\mathrm{Al}, \mathrm{K}^{+}, \mathrm{Ca}^{2+}, \mathrm{Mg}^{2+}$ e V\%, conforme Raij et al. (2001).

As amostras de nitrato $\left(\mathrm{NO}_{3}^{-}\right)$no solo foram coletadas durante a primavera (outubro) antes da semeadura da soja (2003 e 2004) também seguindo o método de Raij et al. (2001). A determinação de ácidos orgânicos foi efetuada nos dois anos de cultivo de aveia-preta, coletando-se a parte aérea de toda planta, na fase de emborrachamento, analisando-se os compostos orgânicos hidrossolúveis de baixo peso molecular de acordo com Amaral et al. (2004a).

Os resultados foram submetidos à análise de variância e posterior regressão, ajustando-se as equações aos dados obtidos, adotando-se como critério para escolha do modelo a interação pelo teste $\mathrm{F}$ significativo a $1 \mathrm{e}$ $5 \%$ e a magnitude dos coeficientes de determinação (Banzatto \& Kronka, 1989), sendo os resultados analisados pelo programa Sigmaplot 8.0. Todos os tratamentos foram comparados com o controle calcário pelo teste de média DMS, a 5 e $1 \%$ de probabilidade (Banzatto \& Kronka, 1989), utilizando o programa Sisvar 4.2.

\section{Resultados e Discussão}

Após três meses da aplicação superficial dos resíduos LC, Lcal e E, ocorreu aumento nos valores de $\mathrm{pH}$ e saturação por bases no solo até a profundidade de $40 \mathrm{~cm}$, sendo a dose de $8 \mathrm{t} \mathrm{ha}^{-1}$ a mais eficiente (Tabelas $4 \mathrm{e} \mathrm{5).}$ Esse efeito benéfico na correção da acidez do solo foi intensificado com o tempo, permanecendo até o $27^{\circ}$ mês de reação no solo, sendo a dose de $8 \mathrm{t} \mathrm{ha}^{-1}$, novamente, a mais eficiente nos três resíduos (LC, Lcal e E). Esses resultados corroboram os de Melo et al. (2001) e Oliveira et al. (2002) para lodo de esgoto incorporado; e os de Prado \& Fernandes (2003) e Carvalho-Pupatto et al. (2004) para escória de aciaria incorporada.

$\mathrm{O}$ aumento dos valores de $\mathrm{pH}$ e da saturação por bases até a profundidade de $40 \mathrm{~cm}$, com o aumento das doses de LC, Lcal e E (Tabelas 4 e 5) ocorreu em razão da maior concentração de compostos resultantes da reação de neutralização, permitindo maior disponibilidade e possibilidade de deslocamento desses compostos, mediante a menor concentração de cátions ácidos na zona de dissolução do corretivo em relação aos outros

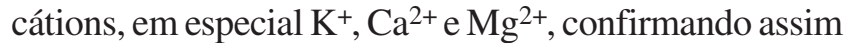
as argüições de Rheinheimer et al. (2000) e Amaral et al. (2004b) sobre calagem superficial. 
Essa maior concentração de compostos resultantes da reação de neutralização, nas doses mais altas dos resíduos LC, Lcal e E (Tabela 5), permite que as cargas negativas do solo, originárias do aumento de $\mathrm{pH}$, sejam preenchidas, disponibilizando o excesso de cátions à solução do solo em menor intervalo de tempo, o que torna possível o deslocamento da frente alcalinizante em subsuperfície, confirmando a afirmação de Caires et al. (2004) para calagem superficial. A maior disponibilidade de cargas negativas variáveis de $\mathrm{pH}$ favorece o deslocamento dos ânions da reação de neutralização da acidez, entre eles $\mathrm{HCO}_{3}{ }^{-}$e $\mathrm{OH}^{-}$, presentes em grandes

Tabela 4. Valores de $\mathrm{pH}$ em $\mathrm{CaCl}_{2}$ decorrentes da aplicação superficial de resíduos e de calcário em um Latossolo Vermelho distrófico sob plantio direto em diferentes profundidades e épocas (meses) de amostragem após a aplicação.

\begin{tabular}{|c|c|c|c|c|c|c|c|c|c|c|c|c|c|}
\hline \multirow[t]{2}{*}{ Tratamento $^{(1)}$} & \multirow{2}{*}{$\begin{array}{l}\text { Dose } \\
\left(\mathrm{t} \mathrm{ha}^{-1}\right)\end{array}$} & \multicolumn{12}{|c|}{ Época (meses) } \\
\hline & & 3 & 15 & 27 & 3 & 15 & 27 & 3 & 15 & 27 & 3 & 15 & 27 \\
\hline & & \multicolumn{3}{|c|}{-------------0-5 cm------------ } & \multicolumn{3}{|c|}{----------5-10 cm---------- } & \multicolumn{3}{|c|}{------------10-20 cm--------- } & \multicolumn{3}{|c|}{-------------20-40 cm----------- } \\
\hline $\mathrm{LC}$ & 2 & 4,5 & 4,8 & 5,7 & 4,7 & 4,5 & 4,7 & 4,4 & 4,4 & 4,7 & 4,1 & 4,5 & 4,2 \\
\hline $\mathrm{LC}$ & 4 & 4,4 & 5,6 & 6,2 & 4,5 & 5,5 & 5,0 & 4,3 & 4,6 & 4,5 & 4,1 & 4,4 & 4,2 \\
\hline $\mathrm{LC}$ & 8 & 5,0 & 7,3 & 6,9 & 5,5 & 6,8 & 6,1 & 4,9 & 5,6 & 5,1 & 4,2 & 5,6 & 4,8 \\
\hline Regressão & & $0,84 * *$ & $0,99 * *$ & $0,96 * *$ & $0,79 * *$ & $0,97 * *$ & $0,99 * *$ & $0,81^{* *}$ & $0,96 * *$ & $0,76^{*}$ & $0,87^{* *}$ & $0,88 * *$ & $0,99 * *$ \\
\hline LB & 2 & 3,9 & 4,3 & 4,8 & 4,1 & 4,1 & 4,1 & 4,2 & 4,1 & 4,2 & 4,0 & 4,2 & 4,2 \\
\hline LB & 4 & 4,1 & 4,5 & 4,8 & 4,3 & 4,2 & 4,3 & 4,3 & 4,0 & 4,3 & 4,0 & 4,4 & 4,2 \\
\hline LB & 8 & 4,1 & 4,3 & 4,6 & 4,2 & 4,1 & 4,2 & 4,3 & 4,0 & 4,2 & 4,0 & 4,0 & 4,2 \\
\hline Regressão & & ns & ns & ns & $\mathrm{ns}$ & ns & $\mathrm{ns}$ & ns & $\mathrm{ns}$ & ns & ns & $\mathrm{ns}$ & ns \\
\hline $\mathrm{E}$ & 2 & 4,2 & 4,8 & 5,1 & 4,6 & 4,5 & 4,7 & 4,4 & 4,3 & 4,7 & 4,3 & 4,3 & 4,4 \\
\hline $\mathrm{E}$ & 4 & 4,4 & 5,2 & 5,6 & 4,9 & 4,5 & 4,6 & 4,7 & 4,4 & 4,5 & 4,4 & 4,6 & 4,6 \\
\hline $\mathrm{E}$ & 8 & 4,5 & 5,6 & 6,4 & 5,2 & 6,0 & 5,5 & 4,7 & 4,7 & 4,6 & 4,5 & 4,6 & 4,7 \\
\hline Regressão & & $0,89^{*}$ & $0,89 * *$ & $0,99 * *$ & $0,99 * *$ & $0,86^{* *}$ & $0,92 * *$ & $0,73^{*}$ & $0,97 * *$ & ns & $0,99 * *$ & $0,74 * *$ & $0,99 * *$ \\
\hline Lcal & 2 & 4,4 & 5,9 & 5,8 & 4,5 & 4,8 & 4,9 & 4,3 & 4,3 & 4,3 & 4,0 & 4,6 & 4,4 \\
\hline Lcal & 4 & 4,4 & 6,4 & 6,4 & 5,2 & 5,1 & 5,0 & 4,6 & 4,6 & 4,6 & 4,3 & 4,7 & 4,4 \\
\hline Lcal & 8 & 5,3 & 6,8 & 7,0 & 6,0 & 5,4 & 6,4 & 5,1 & 5,5 & 5,0 & 4,3 & 4,6 & 4,8 \\
\hline Regressão & & $0,86^{* *}$ & $0,97 * *$ & $0,91 * *$ & $0,97 * *$ & $0,94 * *$ & $0,96 * *$ & $0,93 * *$ & $0,97 * *$ & $0,97 * *$ & $0,76^{* *}$ & $0,91 * *$ & $0,90 * *$ \\
\hline Testemunha & 0 & 4,1 & 4,0 & 4,8 & 4,3 & 4,2 & 4,3 & 4,3 & 4,1 & 4,2 & 3,9 & 4,1 & 4,3 \\
\hline Calcário & 2 & 4,3 & 5,5 & 5,2 & 4,5 & 4,7 & 4,7 & 4,2 & 4,1 & 4,4 & 3,9 & 4,1 & 4,2 \\
\hline CV (\%) & & 6 & 8 & 6 & 8 & 9 & 7 & 6 & 7 & 7 & 3 & 6 & 7 \\
\hline
\end{tabular}

${ }^{(1)}$ LC: lodo de esgoto centrifugado; LB: lodo de esgoto de biodigestor; E: escória de aciaria; Lcal: lama cal. ${ }^{\text {ns} N a ̃ o-s i g n i f i c a t i v o . ~} *$ e $* *$ Significativo a 5 e $1 \%$ de probabilidade, respectivamente.

Tabela 5. Porcentagem de saturação por bases (V\%) de acordo com a aplicação superficial de resíduos e de calcário em um Latossolo Vermelho distrófico sob plantio direto em diferentes profundidades e épocas (meses) de amostragem após a aplicação.

\begin{tabular}{|c|c|c|c|c|c|c|c|c|c|c|c|c|c|}
\hline \multirow[t]{2}{*}{ Tratamento $^{(1)}$} & \multirow{2}{*}{$\begin{array}{l}\text { Dose } \\
\left(\mathrm{t} \mathrm{ha}^{-1}\right)\end{array}$} & \multicolumn{12}{|c|}{ Época (meses) } \\
\hline & & 3 & 15 & 27 & 3 & 15 & 27 & 3 & 15 & 27 & 3 & 15 & 27 \\
\hline & & \multicolumn{3}{|c|}{--------------0-5 cm------------ } & \multicolumn{3}{|c|}{-------------5-10 cm----------- } & \multicolumn{3}{|c|}{---------10-20 cm----------- } & \multicolumn{3}{|c|}{----------20-40 cm-------- } \\
\hline $\mathrm{LC}$ & 2 & 51 & 53 & 73 & 45 & 40 & 49 & 43 & 37 & 44 & 31 & 32 & 43 \\
\hline $\mathrm{LC}$ & 4 & 47 & 90 & 78 & 46 & 70 & 58 & 38 & 39 & 45 & 34 & 32 & 43 \\
\hline $\mathrm{LC}$ & 8 & 58 & 94 & 91 & 69 & 87 & 75 & 50 & 66 & 53 & 50 & 59 & 48 \\
\hline Regressão & & $0,89 * *$ & $0,94 * *$ & $0,95 * *$ & $0,91 * *$ & $0,93 * *$ & $0,99 * *$ & $0,72 * *$ & $0,96 * *$ & $0,89 * *$ & $0,93^{* *}$ & $0,95 * *$ & $0,91 * *$ \\
\hline$\overline{\mathrm{LB}}$ & 2 & 32 & 44 & 49 & 30 & 25 & 32 & 34 & 26 & 32 & 29 & 28 & 34 \\
\hline LB & 4 & 35 & 51 & 57 & 38 & 37 & 36 & 39 & 32 & 35 & 29 & 28 & 34 \\
\hline LB & 8 & 42 & 45 & 55 & 37 & 27 & 35 & 41 & 30 & 36 & 32 & 24 & 35 \\
\hline Regressão & & $0,85^{* *}$ & $0,97^{* *}$ & $0,99 * *$ & ns & $\mathrm{ns}$ & ns & $0,90^{*}$ & ns & ns & $0,95^{*}$ & ns & ns \\
\hline$\overline{\mathrm{E}}$ & 2 & 45 & 65 & 58 & 47 & 42 & 44 & 41 & 41 & 41 & 34 & 31 & 36 \\
\hline E & 4 & 39 & 72 & 75 & 67 & 49 & 52 & 49 & 39 & 45 & 37 & 42 & 45 \\
\hline E & 8 & 54 & 86 & 84 & 72 & 85 & 66 & 51 & 51 & 49 & 47 & 43 & 42 \\
\hline Regressão & & $0,76^{* *}$ & $0,97 * *$ & $0,98 * *$ & $0,87 * *$ & $0,97 * *$ & $0,99 * *$ & $0,99 * *$ & $0,86 * *$ & $0,86 * *$ & $0,95^{* *}$ & $0,95 * *$ & $0,73 *$ \\
\hline Lcal & 2 & 38 & 87 & 80 & 49 & 51 & 47 & 34 & 37 & 37 & 33 & 30 & 38 \\
\hline Lcal & 4 & 37 & 88 & 85 & 60 & 59 & 50 & 39 & 38 & 43 & 34 & 36 & 39 \\
\hline Lcal & 8 & 53 & 87 & 92 & 74 & 64 & 80 & 68 & 62 & 52 & 48 & 38 & 43 \\
\hline Regressão & & $0,89 * *$ & $0,89 * *$ & $0,95 * *$ & $0,99 * *$ & $0,99 * *$ & $0,95 * *$ & $0,92 * *$ & $0,95 * *$ & $0,99 * *$ & $0,95^{* *}$ & $0,81 * *$ & $0,98^{* *}$ \\
\hline Testemunha & 0 & 33 & 35 & 40 & 40 & 27 & 39 & 30 & 26 & 34 & 28 & 25 & 35 \\
\hline Calcário & 2 & 45 & 50 & 64 & 42 & 50 & 62 & 31 & 33 & 45 & 29 & 25 & 35 \\
\hline CV (\%) & & 16 & 8 & 10 & 15 & 18 & 13 & 17 & 20 & 16 & 10 & 13 & 16 \\
\hline
\end{tabular}

(1)LC: lodo de esgoto centrifugado; LB: lodo de esgoto de biodigestor; E: escória de aciaria; Lcal: lama cal. nsNão-significativo. * e **Significativo a 5 e $1 \%$ de probabilidade, respectivamente. 
quantidades, somado ao fato de ter havido adequado volume de precipitação $(2.850 \mathrm{~mm})$, que permitiu a dissolução das partículas dos resíduos e do calcário, bem como a percolação desses íons dissociados por meio de canais radiculares, microcanais biológicos (bioporos) e planos de fraqueza do próprio solo mantidos intactos pelo sistema plantio direto (Amaral et al., 2004b; Fidalski \& Tormena, 2005).

A evolução contínua da correção da acidez em profundidade pelos resíduos LC, Lcal e E, em especial nas maiores doses (Tabela 4), bem como do calcário na dose de $2 \mathrm{t} \mathrm{ha}^{-1}$, está relacionada ao aumento de saturação por bases no solo (Tabela 5). $\mathrm{O}$ deslocamento dos compostos resultantes da reação dos resíduos LC, Lcal, E e do calcário ocorrerá até que eles atinjam a próxima camada ácida e reajam novamente com os cátions ácidos, em especial o $\mathrm{Al}^{3+}$, que tomará o lugar do Ca e $\mathrm{Mg}$ em razão de sua maior força eletrostática, iniciando, assim, o processo de neutralização da acidez, nessas profundidades maiores (Fidalski \& Tormena, 2005).

$\mathrm{O}$ único resíduo que não promoveu variação de $\mathrm{pH}$ no solo foi o LB (Tabela 4). Este resíduo apresenta em sua composição polieletrólitos, como DTPA e EDTA, os quais conferem efeito muito restrito à correção da acidez do solo, pois apresentaram valores de RE, PN e PRNT iguais a 36,5, 3,0 e 1,09, respectivamente (Tabela 3 ). Esses fatores fazem com que o LB não apresente características desejáveis como corretivo de acidez. Em relação à saturação por bases, o aumento das doses de LB, com apenas três meses de reação, proporcionou pequeno incremento neste índice, porém significativo, até a profundidade de $40 \mathrm{~cm}$ e, aos 27 meses, esta elevação de $\mathrm{V} \%$ se restringiu à profundidade de $10 \mathrm{~cm}$ (Tabela 5), estando esses resultados no aumento de $\mathrm{V} \%$, proporcionados pelo LB, relacionados com maior disponibilidade de $\mathrm{Ca}$ e $\mathrm{Mg}$ no perfil do solo.

Os valores de $\mathrm{pH}$ e saturação por bases do solo proporcionado pelo calcário em contraste com a dose zero, na mesma época e para a mesma camada amostrada, denotam que a neutralização da acidez do solo, após três meses de aplicação, se restringe à profundidade de $10 \mathrm{~cm}$ e, com 27 meses, esta frente alcalinizante se deslocou até $20 \mathrm{~cm}$ no perfil do solo (Tabelas 4 e 5), concordando com resultados de Mello et al. (2003), Ciotta et al. (2004), Fidalski \& Tormena, (2005) e Caires et al. (2006), até a profundidade de $20 \mathrm{~cm}$. Quanto ao tratamento-controle, foi aplicada a dose de $2 \mathrm{t} \mathrm{ha}^{-1}$ de calcário, calculada para elevar a saturação por bases a $60 \%$, conferindo-lhe menor concentração de compostos resultantes da reação de neutralização em relação às doses de $4 \mathrm{e} 8 \mathrm{t} \mathrm{ha}^{-1}$ dos resíduos LC, Lcal e E; o PRNT do calcário era de $71,29 \%$ e o da Lcal que era de 98,98\% (Tabela 3), o que permite maior velocidade de reação para o Lcal na mesma dosagem do calcário. A aplicação de doses crescentes de calcário pode ser tão ou mais reativa em profundidade que os resíduos testados.

A eficiência dos resíduos E, Lcal e LC na correção da acidez do solo (Tabela 4) advém da escória de aciaria apresentar silicato em sua composição $\left(\mathrm{SiCO}_{3}\right)$, o qual apresenta solubilidade seis a sete vezes superior à do calcário (Alcarde, 1992), facilitando sua mobilidade no perfil do solo (Quaggio, 2000). A lama cal apresentou os maiores valores de PN e RE quando comparados ao calcário (Tabela 3) em razão de haver em sua composição $\mathrm{NaOH}$ e $\mathrm{CaOH}$, sendo seu ânion da reação de dissociação o hidróxido $\left(\mathrm{OH}^{-}\right)$, o qual apresenta maior solubilidade que o carbonato $\left(\mathrm{HCO}_{3}{ }^{-}\right)$do calcário. $\mathrm{O} \mathrm{LC}$, por receber $\mathrm{CaO}$ (cal virgem) em sua composição, apresenta como ânions dissociáveis óxidos $\left(\mathrm{O}^{2-}\right)$ e hidróxidos $\left(\mathrm{OH}^{-}\right)$, o que confere valor de $\mathrm{PN}$ de $93 \%$, superior ao do calcário utilizado (Tabela 3), e ambos os ânions apresentam maior solubilidade que o carbonato $\left(\mathrm{HCO}_{3}{ }^{-}\right)$.

Todos os resíduos proporcionaram elevação no teor de nitrato no perfil do solo até a profundidade de $40 \mathrm{~cm}$ (Tabela 6), enquanto a calagem elevou o teor de nitrato no solo apenas até a profundidade de $20 \mathrm{~cm}$. Os maiores teores de nitrato contribuem na dinâmica dos nutrientes catiônicos no perfil do solo, pois o ânion $\mathrm{NO}_{3}{ }^{-}$é considerado íon acompanhante de $\mathrm{Ca}^{2+}, \mathrm{Mg}^{2+}$, $\mathrm{K}^{+} \mathrm{e} \mathrm{Al}^{3+}$ (Qafoku \& Sumner, 2001; Rosolem et al., 2003). A movimentação de $\mathrm{Ca}\left(\mathrm{NO}_{3}^{-}\right)_{2}$ ocorre com facilidade, atingindo assim camadas mais profundas do solo e, por serem sais neutros, não aumentam o $\mathrm{pH}$ e nem reduzem a toxidez de $\mathrm{Al}^{3+}$ em subsolo.

A aplicação dos resíduos, bem como da calagem, melhorou o pH e a V\% do solo (Tabelas 4 e 5). Em valores de $\mathrm{pH}\left(\mathrm{CaCl}_{2}\right)$ superiores a 4,0 os mecanismos de mineralização e nitrificação são favorecidos no solo, podendo existir assim maiores teores de nitrato do que de amônio no solo, fato que favorece a lixiviação de nitrato a profundidades de até $60 \mathrm{~cm}$ (Rosolem et al., 2003). Outra razão para o deslocamento do $\mathrm{NO}_{3}{ }^{-}$está relacionada ao fato de os lodos de esgoto serem fonte direta de nitrogênio ao solo (Tabela 1). Houve dois cultivos de soja em 2003 e 2004, sob sistema plantio direto, com aporte ainda maior de nitrogênio, contribuindo desta forma para diminuir as perdas desse nutriente no sistema solo-planta. 
Houve aumento nos teores de $\mathrm{Ca}^{2+}$ no solo em função da elevação das doses dos resíduos E, Lcal e LC em todas as épocas e profundidades amostradas (Tabela 7), devendo-se dar ênfase ao rápido deslocamento desse nutriente no perfil do solo, chegando à profundidade de $40 \mathrm{~cm}$ com apenas três meses de reação. Esse rápido deslocamento do $\mathrm{Ca}^{2+}$ no perfil do solo é razão dos resíduos LC, LB, Lcal e E apresentarem $28,2,37$ e $23 \mathrm{~g}$ de cálcio por $100 \mathrm{~g}$, respectivamente, em suas composições (Tabela 1). O LB não apresentou efeito aos três meses de aplicação na camada de 5-10 cm; em nenhuma camada aos 15 meses; e na camada de 10-20 cm no 27o mês de reação, sendo esses resultados justificados pela menor concentração de $\mathrm{Ca}^{2+}$ em suas composição (Tabela 1).

Tabela 6. Teores de nitrato $\left(\mathrm{N}^{-\mathrm{NO}_{3}{ }^{-} \mathrm{em} \mathrm{mg} \mathrm{dm}}{ }^{-3}\right)$ decorrentes da aplicação superficial de resíduos e de calcário em um Latossolo Vermelho distrófico sob plantio direto em diferentes profundidades e épocas (anos) de amostragem após a aplicação.

\begin{tabular}{|c|c|c|c|c|c|c|c|c|c|}
\hline \multirow[t]{2}{*}{ Tratamento $^{(1)}$} & \multirow{2}{*}{$\begin{array}{l}\text { Dose } \\
\left(\mathrm{t} \mathrm{ha}^{-1}\right)\end{array}$} & \multicolumn{8}{|c|}{ Anos } \\
\hline & & 2003 & 2004 & 2003 & 2004 & 2003 & 2004 & 2003 & 2004 \\
\hline & & \multicolumn{2}{|c|}{---------0-5 cm-------- } & \multicolumn{2}{|c|}{--------5-10 cm-------- } & \multicolumn{2}{|c|}{----10-20 cm----- } & \multicolumn{2}{|c|}{------20-40 cm------ } \\
\hline $\mathrm{LC}$ & 2 & 134 & 153 & 135 & 107 & 126 & 106 & 121 & 111 \\
\hline $\mathrm{LC}$ & 4 & 179 & 169 & 163 & 131 & 142 & 122 & 134 & 144 \\
\hline $\mathrm{LC}$ & 8 & 196 & 188 & 195 & 125 & 161 & 141 & 167 & 157 \\
\hline$\underline{\text { Regressão }}$ & & $0,97 * *$ & $0,97 * *$ & $0,98 * *$ & $0,63 * *$ & $0,96 * *$ & $0,98 * *$ & $0,98^{* *}$ & $0,90 * *$ \\
\hline LB & 2 & 129 & 116 & 131 & 125 & 142 & 132 & 128 & 108 \\
\hline LB & 4 & 159 & 118 & 161 & 121 & 158 & 132 & 148 & 128 \\
\hline LB & 8 & 186 & 153 & 178 & 136 & 158 & 158 & 156 & 146 \\
\hline$\underline{\text { Regressão }}$ & & $0,90 * *$ & $0,90 * *$ & $0,98 * *$ & $0,76^{* *}$ & $0,99 * *$ & $0,84 * *$ & $0,98^{* *}$ & $0,96 * *$ \\
\hline $\mathrm{E}$ & 2 & 135 & 108 & 138 & 128 & 117 & 97 & 126 & 116 \\
\hline $\mathrm{E}$ & 4 & 148 & 137 & 158 & 146 & 137 & 117 & 154 & 144 \\
\hline $\mathrm{E}$ & 8 & 161 & 182 & 154 & 137 & 145 & 145 & 179 & 169 \\
\hline$\underline{\text { Regressão }}$ & & $0,96^{* *}$ & $0,96 * *$ & $0,95 * *$ & $0,99 * *$ & $0,97 * *$ & $0,98 * *$ & $0,97 * *$ & $0,97 * *$ \\
\hline Lcal & 2 & 121 & 103 & 128 & 128 & 123 & 133 & 119 & 101 \\
\hline Lcal & 4 & 134 & 110 & 147 & 157 & 162 & 152 & 135 & 115 \\
\hline Lcal & 8 & 145 & 134 & 156 & 156 & 178 & 198 & 167 & 117 \\
\hline Regressão & & $0,97 *$ & $0,99 * *$ & $0,85^{*}$ & $0,98 * *$ & $0,91 * *$ & $0,97 * *$ & $0,97 * *$ & $0,75^{* *}$ \\
\hline Testemunha & 0 & 116 & 94 & 110 & 100 & 105 & 90 & 114 & 104 \\
\hline Calcário & 2 & 120 & 120 & 125 & 115 & 110 & 130 & 110 & 100 \\
\hline $\mathrm{CV}(\%)$ & & 11 & 9 & 11 & 10 & 12 & 12 & 12 & 9 \\
\hline
\end{tabular}

${ }^{(1)}$ LC: lodo de esgoto centrifugado; LB: lodo de esgoto de biodigestor; E: escória de aciaria; Lcal: lama cal. * e **Significativo a 5 e $1 \%$ de probabilidade, respectivamente.

Tabela 7. Teores de cálcio trocável $\left(\mathrm{mmol}_{\mathrm{c}} \mathrm{dm}^{-3}\right)$ decorrentes da aplicação superficial de resíduos e de calcário em um Latossolo Vermelho distrófico sob plantio direto em diferentes profundidades e épocas (meses) de amostragem após a aplicação.

\begin{tabular}{|c|c|c|c|c|c|c|c|c|c|c|c|c|c|}
\hline \multirow[t]{2}{*}{ Tratamento $^{(1)}$} & \multirow{2}{*}{$\begin{array}{c}\text { Dose } \\
\left(\mathrm{t} \mathrm{ha}^{-1}\right)\end{array}$} & \multicolumn{12}{|c|}{ Época (meses) } \\
\hline & & 3 & 15 & 27 & 3 & 15 & 27 & 3 & 15 & 27 & 3 & 15 & 27 \\
\hline & & \multicolumn{3}{|c|}{------------0-5 cm------------ } & \multicolumn{3}{|c|}{--------5-10 cm-------- } & \multicolumn{3}{|c|}{------------10-20 cm----------- } & \multicolumn{3}{|c|}{-------------20-40 cm----------- } \\
\hline $\mathrm{LC}$ & 2 & 32 & 24 & 31 & 24 & 17 & 23 & 29 & 14 & 21 & 14 & 11 & 18 \\
\hline $\mathrm{LC}$ & 4 & 27 & 84 & 41 & 25 & 43 & 31 & 33 & 18 & 28 & 16 & 15 & 23 \\
\hline $\mathrm{LC}$ & 8 & 39 & 158 & 104 & 57 & 74 & 44 & 39 & 36 & 33 & 40 & 31 & 29 \\
\hline Regressão & & $0,74 *$ & $0,97 * *$ & $0,99 * *$ & $0,98 * *$ & $0,98 * *$ & $0,98 * *$ & $0,82 * *$ & $0,94 * *$ & $0,99 * *$ & $0,99 * *$ & $0,99 * *$ & $0,96 * *$ \\
\hline LB & 2 & 14 & 20 & 18 & 17 & 11 & 14 & 17 & 12 & 13 & 14 & 12 & 17 \\
\hline LB & 4 & 17 & 26 & 26 & 21 & 16 & 15 & 18 & 15 & 15 & 16 & 11 & 16 \\
\hline LB & 8 & 23 & 26 & 26 & 17 & 14 & 16 & 19 & 15 & 14 & 18 & 11 & 18 \\
\hline Regressão & & $0,92 * *$ & ns & $0,81 * *$ & ns & ns & $0,83 *$ & ns & ns & ns & $0,99 * *$ & ns & $0,65^{*}$ \\
\hline $\bar{E}$ & 2 & 19 & 34 & 26 & 28 & 21 & 16 & 22 & 20 & 18 & 19 & 14 & 16 \\
\hline $\mathrm{E}$ & 4 & 22 & 36 & 48 & 57 & 25 & 22 & 34 & 19 & 19 & 21 & 15 & 18 \\
\hline $\mathrm{E}$ & 8 & 35 & 73 & 54 & 68 & 72 & 37 & 38 & 29 & 23 & 27 & 19 & 22 \\
\hline Regressão & & $0,98 * *$ & $0,95 * *$ & $0,95^{* *}$ & $0,94 * *$ & $0,99 * *$ & $0,99 * *$ & $0,89 * *$ & $0,90 * *$ & $0,88^{* *}$ & $0,96^{* *}$ & $0,85^{* *}$ & $0,96 * *$ \\
\hline Lcal & 2 & 19 & 85 & 57 & 21 & 29 & 26 & 19 & 16 & 14 & 15 & 11 & 18 \\
\hline Lcal & 4 & 19 & 68 & 67 & 34 & 30 & 27 & 24 & 20 & 17 & 19 & 17 & 20 \\
\hline Lcal & 8 & 32 & 121 & 121 & 50 & 42 & 62 & 44 & 38 & 28 & 37 & 18 & 24 \\
\hline Regressão & & $0,92 * *$ & $0,81^{* *}$ & $0,96^{* *}$ & $0,97 * *$ & $0,92 * *$ & $0,93 * *$ & $0,97 * *$ & $0,96 * *$ & $0,96 * *$ & $0,99 * *$ & $0,85^{* *}$ & $0,93 * *$ \\
\hline Testemunha & 0 & 14 & 14 & 11 & 18 & 9 & 11 & 13 & 10 & 12 & 12 & 11 & 12 \\
\hline Calcário & 2 & 22 & 40 & 42 & 24 & 21 & 25 & 21 & 14 & 15 & 13 & 12 & 12 \\
\hline $\mathrm{CV}(\%)$ & & 13 & 20 & 10 & 17 & 17 & 15 & 18 & 19 & 16 & 13 & 17 & 18 \\
\hline
\end{tabular}

${ }^{(1)}$ LC: lodo de esgoto centrifugado; LB: lodo de esgoto de biodigestor; E: escória de aciaria; Lcal: lama cal. ns Não-significativo. $*$ e $* *$ Significativo a 5 e $1 \%$ de probabilidade, respectivamente. 
O deslocamento de $\mathrm{Ca}^{2+}$ no perfil do solo, pelos resíduos E, Lcal e LC (Tabelas 7), pode ser atribuído à alta concentração do nutriente nas camadas superficiais e por não haver cátions ácidos nas camadas subsuperficiais devido à correção do $\mathrm{pH}$ até a profundidade de $40 \mathrm{~cm}$ (Tabela 4), bem como a formação de compostos iônicos, em especial o nitrato (Tabela 6). O deslocamento do Ca-ligante e do Mg-ligante para camadas subsuperficiais só ocorre quando a constante de estabilidade do complexo é maior que a constante de estabilidade do cálcio-solo e do magnésio-solo (Amaral et al., 2004b).

O calcário aplicado em superfície após 27 meses de reação mostrou aumento nos teores de cálcio até $20 \mathrm{~cm}$ (Tabela 7), e nessa mesma profundidade encontram-se a reação de neutralização do solo (Tabela 4) e o índice de saturação por bases (Tabela 5) para o tratamento calcário, confirmando os resultados de Caires et al. (2004), Ciotta et al. (2004) e Fidalski \& Tormena (2005) com aplicação de calagem superficial até $20 \mathrm{~cm}$ de profundidade.

O aumento das doses dos resíduos LC, LB, Lcal e E permitiu constatar aumento significativo no teor de $\mathrm{Mg}^{2+}$ no solo até a profundidade de $40 \mathrm{~cm}$, com apenas três meses de reação (Tabela 8). Esse rápido deslocamento do $\mathrm{Mg}^{2+}$ no perfil do solo decorrente do aumento nas doses dos resíduos refletiu em efeito não-significativo dessa variável aos 15 meses de reação, com exceção apenas na camada de $0-5 \mathrm{~cm}$ para os resíduos LC e E e na camada de $5-10 \mathrm{~cm}$ para E. Esse comportamento pode ser atribuído aos altos teores de $\mathrm{Ca}^{2+}$ no solo (Tabela 7) em comparação ao $\mathrm{Mg}^{2+}$, promovendo maior adsorção do $\mathrm{Ca}^{2+}$ ao solo, o que pode ter forçado o deslocamento do $\mathrm{Mg}^{2+}$ a profundidades maiores que $40 \mathrm{~cm}$.

A maior contribuição da aplicação superficial dos resíduos LC, LB, Lcal e E, no aumento do teor de $\mathrm{Mg}^{2+}$ no solo, decorrente do aumento de suas doses, foi verificado na superfície do solo, demonstrado pelo efeito significativo na camada de $0-5 \mathrm{~cm}$ aos 27 meses de reação. Esse comportamento pode ser justificado pela ciclagem do $\mathrm{Mg}^{2+}$ pelos dois cultivos de soja e de aveiapreta, com as raízes dessas plantas atuando como "bomba biológica" que absorve $\mathrm{o} \mathrm{Mg}^{2+} \mathrm{em}$ maiores profundidades, transferindo-o para a parte aérea. Após a decomposição dos restos culturais pode ter ocorrido o retorno desse nutriente ao solo, elevando assim seu teor na superfície. Em nenhum momento, o teor de $\mathrm{Mg}^{2+}$ no solo ficou abaixo de $5 \mathrm{mmol}_{\mathrm{c}} \mathrm{dm}^{-3}$, considerado baixo para o desenvolvimento das culturas (Raij et al., 1996).

A prática da calagem foi um dos melhores tratamentos no deslocamento do $\mathrm{Mg}$ até a profundidade de $20 \mathrm{~cm}$, em razão de o calcário empregado apresentar $230 \mathrm{~g} \mathrm{~kg}^{-1} \mathrm{de} \mathrm{MgO}$, confirmando os resultados obtidos por Caires et al. (2004) e Fidalski \& Tormena (2005). O aumento no teor de $\mathrm{Mg}^{2+}$

Tabela 8. Teores de magnésio trocável decorrentes da aplicação superficial de resíduos e de calcário em um Latossolo Vermelho distrófico sob plantio direto em diferentes profundidades e épocas (meses) de amostragem após a aplicação.

\begin{tabular}{|c|c|c|c|c|c|c|c|c|c|c|c|c|c|}
\hline \multirow[t]{2}{*}{ Tratamento $^{(1)}$} & \multirow{2}{*}{$\begin{array}{c}\text { Dose } \\
\left(\mathrm{t} \mathrm{ha}^{-1}\right)\end{array}$} & \multicolumn{12}{|c|}{ Época (meses) } \\
\hline & & 3 & 15 & 27 & 3 & 15 & 27 & 3 & 15 & 27 & 3 & 15 & 27 \\
\hline & & \multicolumn{3}{|c|}{--------0-5 cm--------- } & \multicolumn{3}{|c|}{---------5-10 cm--------- } & \multicolumn{3}{|c|}{------10-20 cm------- } & \multicolumn{3}{|c|}{$-----20-40 \mathrm{~cm}---$} \\
\hline $\mathrm{LC}$ & 2 & 7 & 9 & 11 & 7 & 8 & 5 & 9 & 8 & 7 & 4 & 8 & 6 \\
\hline $\mathrm{LC}$ & 4 & 7 & 11 & 11 & 8 & 7 & 6 & 7 & 6 & 5 & 6 & 6 & 5 \\
\hline $\mathrm{LC}$ & 8 & 8 & 12 & 11 & 9 & 8 & 7 & 10 & 8 & 8 & 6 & 8 & 5 \\
\hline Regressão & & $0,79 * *$ & $0,89 *$ & $0,92 * *$ & $0,90^{*}$ & ns & ns & $0,67 *$ & ns & ns & $0,83 * *$ & ns & ns \\
\hline LB & 2 & 6 & 9 & 10 & 6 & 5 & 5 & 5 & 6 & 6 & 4 & 6 & 4 \\
\hline LB & 4 & 6 & 11 & 11 & 7 & 7 & 7 & 7 & 7 & 7 & 5 & 6 & 5 \\
\hline LB & 8 & 7 & 7 & 11 & 7 & 6 & 5 & 7 & 7 & 8 & 6 & 5 & 5 \\
\hline Regressão & & ns & ns & $0,96 * *$ & $\mathrm{~ns}$ & ns & ns & ns & $\mathrm{ns}$ & $0,97 * *$ & $0,92 * *$ & $\mathrm{~ns}$ & ns \\
\hline $\mathrm{E}$ & 2 & 7 & 14 & 9 & 10 & 7 & 7 & 7 & 7 & 7 & 6 & 8 & 7 \\
\hline E & 4 & 8 & 17 & 17 & 13 & 10 & 9 & 10 & 9 & 9 & 7 & 7 & 9 \\
\hline E & 8 & 10 & 27 & 20 & 18 & 8 & 13 & 11 & 8 & 9 & 7 & 8 & 7 \\
\hline Regressão & & $0,94 * *$ & $0,99 * *$ & $0,89 * *$ & $0,90 * *$ & $0,96^{*}$ & $0,99 * *$ & $0,80 * *$ & ns & $0,81 * *$ & $0,73 * *$ & ns & $0,98 *$ \\
\hline Lcal & 2 & 6 & 12 & 12 & 6 & 8 & 6 & 5 & 5 & 5 & 5 & 5 & 5 \\
\hline Lcal & 4 & 6 & 8 & 15 & 8 & 6 & 6 & 6 & 8 & 6 & 5 & 8 & 6 \\
\hline Lcal & 8 & 7 & 9 & 17 & 11 & 6 & 10 & 8 & 8 & 6 & 6 & 7 & 7 \\
\hline Regressão & & ns & ns & $0,99 * *$ & $0,91 * *$ & ns & $0,80^{*}$ & $0,83 * *$ & ns & $\mathrm{ns}$ & $0,86^{*}$ & ns & $0,95^{*}$ \\
\hline Testemunha & 0 & 5 & 8 & 6 & 6 & 5 & 6 & 5 & 6 & 6 & 4 & 8 & 5 \\
\hline Calcário & 2 & 9 & 27 & 16 & 6 & 11 & 15 & 5 & 9 & 10 & 5 & 8 & 5 \\
\hline $\mathrm{CV}(\%)$ & & 24 & 18 & 17 & 25 & 22 & 26 & 19 & 32 & 18 & 20 & 36 & 22 \\
\hline
\end{tabular}

${ }^{(1)}$ LC: lodo de esgoto centrifugado; LB: lodo de esgoto de biodigestor; E: escória de aciaria; Lcal: lama cal. ${ }^{\text {ns Não-significativo. } * \text { e } * * \text { Significativo }}$ a 5 e $1 \%$ de probabilidade, respectivamente. 
decorrente da aplicação dos resíduos é razão também do aumento de $\mathrm{pH}$ no solo (Tabela 4), que favorece a formação de cargas negativas e, conseqüentemente, a maior adsorção, principalmente para os resíduos E, LC e Lcal.

Assim, a evolução contínua da correção da acidez do solo até as camadas mais profundas $(40 \mathrm{~cm})$, proporcionada pela aplicação superficial dos resíduos LC, Lcal e, em especial nas maiores doses, sob sistema plantio direto (Tabela 4), permitiu a mobilização dos íons $\mathrm{NO}_{3}{ }^{-}, \mathrm{Ca}^{2+}$ e $\mathrm{Mg}^{2+}$ (Tabelas 6, 7 e 8) e do índice de saturação por bases no perfil do solo (Tabela 5), confirmando as afirmações de Fidalski \& Tormena (2005) para calagem superficial.

A aplicação superficial dos resíduos e do calcário em sistema de plantio direto aumentou os teores dos ácidos aconítico, oxálico, cítrico e maciço presentes na parte aérea da aveia-preta (Tabela 9), com exceção do ácido cítrico para LB em 2004. Esses quatro ácidos orgânicos somados produzem, no máximo, um total de $10 \mathrm{~kg} \mathrm{ha}^{-1}$ de compostos orgânicos hidrossolúveis de baixo peso molecular, para uma produção média de massa de matéria seca de $4.000 \mathrm{~kg} \mathrm{ha}^{-1}$. Já Amaral et al. (2004a) relatam $144 \mathrm{~kg} \mathrm{ha}^{-1}$ de compostos hidrossolúveis de baixo peso molecular para um total de massa de matéria seca de $10.000 \mathrm{~kg} \mathrm{ha}^{-1}$.

As quantidades médias de compostos orgânicos hidrossolúveis de baixo peso molecular presentes na aveiapreta foram de 1,6 $\mathrm{kg} \mathrm{ha}^{-1}$ de ácido aconítico, $1,1 \mathrm{~kg} \mathrm{ha}^{-1}$ de ácido oxálico, $0,8 \mathrm{~kg} \mathrm{ha}^{-1}$ de ácido cítrico e 1,2 $\mathrm{kg} \mathrm{ha}^{-1}$ de ácido maciço (Tabela 9), considerando-se a produção média de massa de matéria seca da aveia-preta de $4.000 \mathrm{~kg} \mathrm{ha}^{-1}$. Esses resultados foram inferiores aos relatados por Amaral et al. (2004a), que encontraram valores de 97,4 $\mathrm{kg} \mathrm{ha}^{-1}$ de ácido transaconítico, $9 \mathrm{~kg} \mathrm{ha}^{-1}$ de ácido oxálico, $36 \mathrm{~kg} \mathrm{ha}^{-1}$ de ácido cítrico e não encontraram o ácido málico; esses valores foram estimados do total de $10.000 \mathrm{~kg} \mathrm{ha}^{-1}$ de massa de matéria seca de aveia-preta.

A pequena quantidade de ácidos orgânicos encontrada na parte área da aveia-preta não justifica o deslocamento da frente alcalinizante até a profundidade de $40 \mathrm{~cm}$ (Tabela 4), tampouco o deslocamento de $\mathrm{Ca}$ e $\mathrm{Mg}$ (Tabelas 7 e 8), não confirmando resultados obtidos por Franchini et al. (2001, 2003), conduzidos sob condições controladas e corroborando os resultados de Caires et al. (2006) em trabalho conduzido em campo.

É provável que os pares iônicos inorgânicos com nitrato (Tabela 6) e outros como $\mathrm{HCO}_{3}{ }^{-}, \mathrm{OH}^{-}$ (Rheinheimer et al., 2000), $\mathrm{Cl}^{-} \mathrm{e} \mathrm{SO}_{4}{ }^{2-}$ (Caires et al., 1998) tenham maior atuação no deslocamento de cátions, quando comparados aos orgânicos, em razão da maior quantidade desses íons no solo (Meda et al., 2002), e por serem mais estáveis dentro de uma faixa ampla de pH (Bayer \& Mielniczuk, 1999), permanecendo a atuação dos ácidos orgânicos de baixo peso molecular restrita à camada superficial até $2,5 \mathrm{~cm}$ (Amaral et al., 2004a).

Tabela 9. Quantidade de ácidos orgânicos de baixo peso molecular ( $\mathrm{g}$ ha ${ }^{-1}$ ) presentes na aveia-preta em 2003 e 2004 , em função da aplicação superficial de resíduos e de calcário em duas épocas (anos) de amostragem após a aplicação.

\begin{tabular}{|c|c|c|c|c|c|c|c|c|c|}
\hline \multirow[t]{2}{*}{ Tratamento $^{(1)}$} & \multirow{2}{*}{$\begin{array}{c}\text { Dose } \\
\left(\mathrm{t} \mathrm{ha}^{-1}\right)\end{array}$} & \multicolumn{8}{|c|}{ Anos } \\
\hline & & 2003 & 2004 & 2003 & 2004 & 2003 & 2004 & 2003 & 2004 \\
\hline & & \multicolumn{2}{|c|}{-------0-5 cm------- } & \multicolumn{2}{|c|}{-------5-10 cm------- } & \multicolumn{2}{|c|}{--------10-20 cm-------- } & \multicolumn{2}{|c|}{-------20-40 cm-------- } \\
\hline $\mathrm{LC}$ & 2 & 1.797 & 2.345 & 696 & 1.592 & 1.075 & 776 & 1.278 & 1.192 \\
\hline $\mathrm{LC}$ & 4 & 1.869 & 3.418 & 813 & 1.950 & 1.093 & 1.046 & 1.383 & 1.632 \\
\hline $\mathrm{LC}$ & 8 & 1.994 & 3.501 & 920 & 2.166 & 1.201 & 1.079 & 1.719 & 1.411 \\
\hline Regressão & & $0,92 * *$ & $0,98 * *$ & $0,98 * *$ & $0,99 * *$ & $0,97 * *$ & $0,86 * *$ & $0,94 * *$ & $0,98 * *$ \\
\hline LB & 2 & 1.122 & 1.913 & 598 & 1.314 & 796 & 928 & 1.186 & 1.654 \\
\hline LB & 4 & 1.164 & 1.808 & 631 & 1.277 & 814 & 863 & 1.292 & 1.639 \\
\hline LB & 8 & 1.266 & 2.094 & 658 & 1.440 & 897 & 1.064 & 1.555 & 1.817 \\
\hline Regressão & & $0,91 * *$ & $0,84^{*}$ & $0,96 * *$ & $0,96 * *$ & $0,94 * *$ & ns & $0,94 * *$ & $0,89 *$ \\
\hline $\mathrm{E}$ & 2 & 2.514 & 2.235 & 1.200 & 1.622 & 1.401 & 852 & 1.454 & 2.061 \\
\hline $\mathrm{E}$ & 4 & 3.494 & 2.263 & 2.239 & 1.819 & 1.594 & 961 & 1.973 & 2.214 \\
\hline $\mathrm{E}$ & 8 & 3.444 & 2.670 & 2.230 & 1.834 & 1.618 & 1.122 & 2.067 & 2.521 \\
\hline Regressão & & $0,96 * *$ & $0,95 * *$ & $0,95 * *$ & $0,99 * *$ & $0,99 * *$ & $0,99 * *$ & $0,97 * *$ & $0,97 * *$ \\
\hline Lcal & 2 & 1.819 & 1.722 & 1.065 & 2.083 & 1.052 & 874 & 1.541 & 1.960 \\
\hline Lcal & 4 & 1.980 & 2.187 & 1.564 & 2.227 & 1.139 & 973 & 1.713 & 1.940 \\
\hline Lcal & 8 & 2.531 & 2.650 & 1.766 & 2.558 & 1.398 & 1.065 & 2.053 & 2.305 \\
\hline Regressão & & $0,96 * *$ & $0,98 * *$ & $0,99 * *$ & $0,98 * *$ & $0,97 * *$ & $0,91 * *$ & $0,95 * *$ & $0,99 * *$ \\
\hline Testemunha & 0 & 980 & 1.447 & 478 & 780 & 644 & 725 & 365 & 420 \\
\hline Calcário & 2 & 1.800 & 2.400 & 900 & 1.400 & 800 & 800 & 1.000 & 1.500 \\
\hline CV (\%) & & 19 & 21 & 25 & 22 & 15 & 12 & 17 & 16 \\
\hline
\end{tabular}

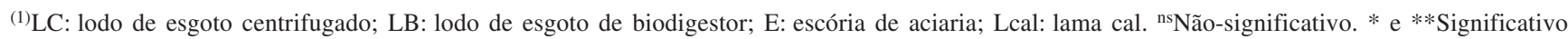
a 5 e $1 \%$ de probabilidade. 


\section{Conclusões}

1. A aplicação superficial de doses crescentes de escória de aciaria, lama cal e lodo de esgoto centrifugado aumenta os valores de $\mathrm{pH}$ no solo, e esses três resíduos e o lodo de esgoto de biodigestor também aumentam a saturação por bases e a disponibilidade de nitrato, cálcio e magnésio até a profundidade de $40 \mathrm{~cm}$ no solo, com apenas três meses de reação.

2. A correção da acidez em subsuperfície decorrente do aumento das doses dos resíduos escória de aciaria, lama cal e lodo de esgoto centrifugado, associada ao aumento dos teores de nitrato no perfil do solo por esses resíduos mais o lodo de esgoto de biodigestor, favorece o deslocamento de cálcio e magnésio até a profundidade de $40 \mathrm{~cm}$.

3. Os resíduos escória de aciaria, lama cal e lodo de esgoto centrifugado podem ser utilizados como corretivos da acidez e aplicados sobre a superfície do solo no sistema de plantio direto.

4. O efeito da calagem superficial, na dose de $2 \mathrm{tha}^{-1}$, nas variáveis $\mathrm{pH}$, saturação por bases, nitrato, cálcio e magnésio está restrito à profundidade de $20 \mathrm{~cm}$, após 27 meses de reação.

\section{Agradecimentos}

À Fapesp, pela bolsa de estudo e pelo apoio financeiro.

\section{Referências}

ALCARDE, J.C. Corretivos da acidez dos solos: características e interpretações técnicas. São Paulo: ANDA, 1992. 62p. (Boletim Técnico, 6).

ALLEONI, L.R.F.; CAMBRI, M.A.; CAIRES, E.F. Atributos químicos de um Latossolo de cerrado sob plantio direto, de acordo com doses e formas de aplicação de calcário. Revista Brasileira de Ciência do Solo, v.29, p.923-934, 2005.

AMARAL, A.S.; ANGHIONI, I.; DESCHAMPS, F.C. Resíduos de plantas de cobertura e do calcário aplicado na superfície do solo. Revista Brasileira de Ciência do Solo, v.28, p.115-123, 2004a.

AMARAL, A.S.; ANGHIONI, I.; HINRICHIS, R.; BERTOL, I. Movimentação de partículas de calcário no perfil de um Cambissolo em plantio direto. Revista Brasileira de Ciência do Solo, v.28, p.359-367, 2004b.

BANZATTO, D.A.; KRONKA, S.N. Experimentação agrícola. Jaboticabal: Funep, 1989. 247p.

BAYER, C.; MIELNICZUK, J. Dinâmica e função da matéria orgânica. In: SANTOS, G. de A.; CAMARGO, F.A. de O. (Ed.). Fundamentos da matéria orgânica do solo: ecossistemas tropicais e subtropicais. Porto Alegre: Gênesis, 1999. p.9-26.
CAIRES, E.F.; GARBUIO, F.J.; ALLEONI, L.R.F.; CAMBRI, M.A. Calagem superficial e cobertura de aveia preta antecedendo os cultivos de milho e soja em sistema de plantio direto. Revista Brasileira de Ciência do Solo, v.30, p.87-98, 2006.

CAIRES, E.F.; KUSMAM, M.T.; BARTH, G.; GARBUIO, F.G.; PADILHA, J.M. Alterações químicas do solo e resposta do milho à calagem e aplicação de gesso. Revista Brasileira de Ciência do Solo, v.28, p.125-136, 2004.

CAIRES, E.F.; MADRUGA, E.F.; CHUEIRI, W.A.; FIGUEIREDO, A. Alterações das características químicas do solo e respostas da soja ao calcário e gesso aplicados na superfície em sistema de cultivo sem preparo do solo. Revista Brasileira de Ciência do Solo, v.22, p.27-34, 1998.

CARVALHO-PUPATTO, J.G; BÜLL, L.T.; CRUSCIOL, C.A.C. Atributos químicos do solo, crescimento radicular e produtividade do arroz de acordo com a aplicação de escórias. Pesquisa Agropecuária Brasileira, v.39, p.1213-1218, 2004.

CETESB. Aplicação de lodos de sistemas de tratamento biológico em áreas agrícolas: critérios para projeto e operação. São Paulo: Cetesb, 1999. 32p. (Norma P 4230).

CIOTTA, M.N.; BAYER, C.; ERNANI, P.R.; FONTOURA, S.M.V.; WOBETO, C.; ALBUQIERQUE, J.A. Manejo da calagem e os componentes da acidez de Latossolos Bruno em plantio direto. Revista Brasileira de Ciência do Solo, v.28, p.317-326, 2004.

EMBRAPA. Sistema Brasileiro de classificação de solos. Brasília: Embrapa Produção de Informação; Rio de Janeiro: Embrapa Solos. 1999. 412p.

FIDALSKI, J.; TORMENA, C.A. Dinâmica da calagem superficial em um Latossolo Vermelho distrófico. Revista Brasileira de Ciência do Solo, v.29, p.235-247, 2005.

FRANCHINI, J.C.; GONZALEZ-VILLA, F.J.; MIYAZAWA, M.; PAVAN, M.A. Rapid transformations of plant water soluble organic componds in relation to cation mobilization in acid Oxisol. Plant and Soil, v.231, p.55-63, 2001.

FRANCHINI, J.C.; HOFFMANN-CAMPO, C.B.; TORRES, E.; MIYAZAWA, M.; PAVAN, M.A. Organic composition of green manures during growth and its effect on cation mobilization in an acid oxisol. Communications in Soil Science and Plant Analysis, v.34, p.2045-2058, 2003.

LABORATÓRIO NACIONAL DE REFERÊNCIA VEGETAL LANARV. Análise de corretivos, fertilizantes e inoculantes: métodos oficiais. Brasília: Ministério da Agricultura, 1983. 104p.

MEDA, A.R.; PAVAN, M.A.; MIYAZAWA, M.; CASSIOLATO, M.E. Plantas invasoras para melhor eficiência da calagem na correção da acidez subsuperficial do solo. Revista Brasileira de Ciência do Solo, v.26, p.647-654, 2002.

MELLO, J.C.A.; VILLAS-BOAS, R.L.; LIMA, E.V.; CRUSCIOL, C.A.C.; BÜLL, L.T. Alterações nos atributos químicos de um Latossolo Distroférrico decorrentes da granulometria e doses de calcário em sistemas plantio direto e convencional. Revista Brasileira de Ciência do Solo, v.27, p.553-561, 2003. 
MELO, W.J.; MARQUES, M.O.; MELO, V.P. O uso agrícola do biossólido e as propriedades do solo. In:TSUTIYA, M.T.; COMPARINI, J.P.; ALEM SOBRINHO, P.; HESPANHOL, I.; CARVALHO, P.C.T.; MELFI, A.J.; MELO, W.J.; MARQUES, M.O. (Ed.). Biossólidos na agricultura. São Paulo: Sabesp, 2001. p.289-363.

NASCIMENTO, C.W.A.; BARROS, D.A.S.; MELO, E.E.C.; OLIVEIRA, A.B. Alterações químicas em solos e crescimento de milho e feijoeiro após aplicação de lodo de esgoto. Revista Brasileira de Ciência do Solo, v.28, p.385-392, 2004.

OLIVEIRA, F.C.; MATTIAZZO, M.E.; MARCIANO, C.R.; ROSSETO, R. Efeitos de aplicações sucessivas de lodo de esgoto em Latossolo Amarelo distrófico cultivado com cana-de-açúcar: carbono orgânico, condutividade elétrica, pH e CTC. Revista Brasileira de Ciência do Solo, v.26, p.505-519, 2002.

PRADO, R. de M.; FERNANDES, F.M. Efeito residual da escória de siderurgia como corretivo de acidez do solo na soqueira de canade-açúcar. Revista Brasileira de Ciência do Solo, v.27, p.287296, 2003.

QAFOKU, N.P.; SUMNER, M.E. Retention and transport of calcium nitrate in variable charge subsoils. Soil Science, v.166, p.297-307, 2001.

QUAGGIO, J.A. Acidez e calagem em solos tropicais. Campinas: Instituto Agronômico, 2000. 111p.

RAIJ, B. van; ANDRADE, J.C.; CANTARELLA, H.; QUAGGIO, J.A. Análise Química para avaliação da fertilidade de solos tropicais. Campinas: Instituto Agronômico, 2001. 285p.
RAIJ, B. van; CANTARELLA, H.; QUAGGIO, J.A.; FURLANI, A.M.C. Recomendações de adubação e calagem para o estado de São Paulo. 2.ed. Campinas: Instituto Agronômico; Fundação IAC, 1996. 285p. (Boletim Técnico, 100).

RAMOS, L.A.; NOLLA, A.; KORNDÖRFER, G.H.; PEREIRA, H.S.; CAMARGO, M.S. Reatividade de corretivos da acidez e condicionadores de solo em colunas de lixiviação. Revista Brasileira de Ciência do Solo, v.30, p.849-857, 2006.

RHEINHEIMER, D.S.; SANTOS, E.J.S.; KAMINSKI, J.; BORTOLUZZI, E.C.; GATIBONI, L.C. Alterações de atributos do solo pela calagem superficial e incorporada a partir de pastagem natural. Revista Brasileira de Ciência do Solo, v.24, p.797-805, 2000.

ROSOLEM, C.A.; FOLONI, J.S.S.; OLIVEIRA, R.H. Dinâmica do nitrogênio no solo em razão da calagem e adubação nitrogenada, com palha na superfície. Pesquisa Agropecuária Brasileira, v.38, p.301309, 2003.

SÚMULA DOS PADRÕES LEGAIS VIGENTES PARARESÍDUOS SÓLIDOS: NBR 10004/1987. Disponível em: http:// www.bolsaderesiduos.org.br/normas_01.htm. Acesso em: 30 ago. 2006.

TSUTIYA, M.T.; COMPARINI, J.P.; ALEM SOBRINHO, P.; HESPANHOL, I.; CARVALHO, P.C.T.; MELFI, A.J.; MELO, W.J.; MARQUES, M.O. Biossólidos na agricultura. São Paulo: Sabesp, 2001. 468p.

$\overline{\text { Recebido em } 25 \text { de outubro de } 2006 \text { e aprovado em } 15 \text { de agosto de } 2007}$ 